\title{
Morphological features and endodontic treatment in taurodontism
}

\author{
Caracteristicile morfologice şi tratamentul endodontic în taurodontism
}

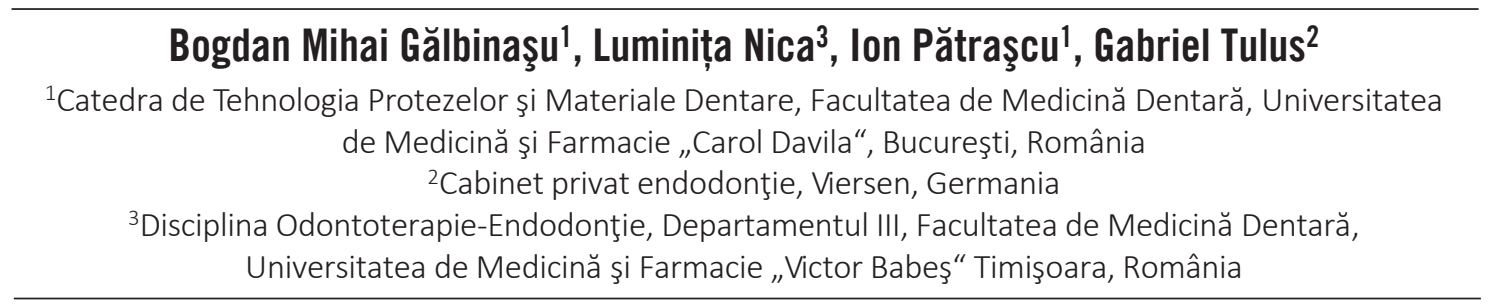

\begin{abstract}
The goal of endodontic treatment is the removing of pathological tissues and bacterias from the root canal system. The major obstacle is achieving this goal is represented by branched root canal systems, sometimes this is more difficult due to atypical tooth anatomy or tooth anomaly. This article presents a complex case of a lower premolar with multiple root canals and a dental anomaly.
\end{abstract}

Keywords: taurodontism, access cavity, branched root canal systems, dental operating microscope, intracanal endodontic diagnostics, tooth anatomy, root filling

\section{REZUMAT}

Obiectivul major în cazul tratamentului endodontic este reprezentat de îndepărtarea țesutului pulpar și a eventualelor microorganisme prezente în sistemul endodontic al canalului radicular. Unul dintre principalele obstacole este reprezentat de complexitatea anatomică a dintelui de tratat, dificultatea sporind în situațiile cu anatomie „atipică“ sau prezența de anomalii. Acest articol prezintă un caz clinic complex la un premolar inferior cu anatomie particulară, respectiv mai mult de un canal radicular și prezența unei anomalii.

Cuvinte cheie: taurodontism, cavitate de acces, sistem endodontic radicular, microscop dentar, diagnostic endodontic, anatomie dentară, obturație de canal

\section{INTRODUCERE}

Taurodontismul poate fi definit că o modificare a formei dintelui, ce are drept cauză absenţa invaginării tecii radiculare epiteliale Hertwig la nivelul corespunzător. Din acest motiv, principalele caracteristici ale dinţilor cu taurodontism vor fi reprezentate de o cameră pulpară mai mare, o deplasare către apical a furcaţiei radiculare şi lipsa constricţiei pulpare la nivelul coletului (8).

Incidenţa taurodontismului prezintă o mare variabilitate, probabil din cauza lipsei de standardizare a criteriilor de evaluare, precum şi din cauza variabilităţii în funcţie de grupurile biologice de populaţii. Incidenţa maximă, de $48 \%$, este descrisă de Saar et al., în urma unui studiu la nivelul populaţiei tinere senegaleze între 15 şi 19 ani (18). O incidenţă asemănătoare, de 46,4\%, este descrisă de Macdonald-Jankowski la populaţia chineză adultă tânără (16). Într-un studiu la nivelul populaţiei nord-indiene pe 1.000 de pacienţi, cu un total de 7.615 molari, au fost găsiţi 28 de pacienţi cu dinţi care prezintă taurodontism, respectiv $2,8 \%$, la analiza numărului de dinţi cu taurodontism fiind găsiţi 80 , respectiv $1,05 \%$ din totalul dinţilor, cu frecvenţă maximă la molarii de minte (1). Studiile făcute la nivelul populaţiei caucaziene (europene) arată o incidenţă apropiată a taurodontismului cu a populaţiei indiene. Bürklein et al. au găsit în urma evaluă- 
rii radiografiilor panoramice a 4.885 de molari aparţinând unui număr de 800 de pacienţi adulţi prezenţa de dinţi cu taurodontism la 18 pacienţi $(2,25 \%)$ şi un procent de $0,61 \%$ din numărul total de molari analizaţi (3). În ceea ce priveşte localizarea pe grupuri dentare, există discrepanţe între studii. În timp ce în anumite studii sunt descrise cazuri de taurodontism numai la molari $(3,17)$, există şi descrierea acestei anomalii la nivelul premolarilor. Astfel, într-o analiză a 379 de premolari extraşi, au fost găsiţi 3 premolari cu taurodontism (15), ceea ce reprezintă $0,79 \%$, cifră apropiată de incidenţa la nivelul molarilor descrisă de Bürklein et al.

În ceea ce priveşte incidenţa premolarilor inferiori cu trei canale radiculare, studiile existente prezintă o prevalenţă între 0 şi 5\%, cu o frecvenţă mai mică la nivelului premolarului al doilea mandibular (11) şi diferenţe semnificative în funcţie de rasă/tip de populaţie, frecvenţa fiind mai redusă la populaţia caucaziană şi mai ridicată la populaţia asiatică din China şi la populaţia de culoare din Statele Unite. Conform datelor actuale, incidenţa premolarilor inferiori cu trei canale radiculare este de $0,4 \%$ $(7,25)$.

\section{PREZENTAREA CAZULUI}

Un pacient în vîrsta de 36 de ani se prezintă la endodontolog $\mathrm{cu}$ trimitere pentru tratamentului dintelui 35, acuzând simptomatologie dureroasă persistentă. Din anamneză şi din biletul de trimitere reiese că, în baza diagnosticului de pulpită simptomatică ireversibilă, dintele 35 a fost trepanat, însă nu s-a reuşit permeabilizarea canalului radicular pe toată lungimea. Ca medicament intracanalar, a fost folosit, în urma trepanării dintelui, un amestec de corticoid şi antibiotic local (Ledermix - Riemser, Riems, Germany), obţinându-se doar ameliorarea durerii. Anamneza generală nu prezintă informaţii relevante. În cursul discuţiei anamnestice, pacientul acuza dureri atât la modificări de temperatură, cât şi la presiune înaintea tratamentului iniţial, cu exacerbări spontane. Conform afirmaţiilor pacientului, terapia cu antialgice reduce durerea la presiune, însă nu elimină sensibilitatea la temperatură. După tratamentul iniţial, persistă numai sensibilitatea la presiune. În cadrul examenului clinic, se remarcă prezenţa unei obturaţii provizorii masive ocluzale şi a unei obturaţii cu ciment ocluzo-dista- le. La sondarea circulară nu se constată valori de profunzime patologice, în cele opt puncte sondate valorile oscilând între 3,0 şi 3,5 mm. Testul la percuţie duce la exacerbarea durerii. Analiza radiografiei intraorale efectuate după examenul clinic arată o alungire a camerei pulpare până la nivelul inferior al treimii medii a rădăcinii, semnele unei morfologii atipice cu două rădăcini de lungimi apropiate, iar canalele radiculare nu sunt complet decelabile radiologic sub nivelul separaţiei rădăcinilor. $\mathrm{Nu}$ se constată reacţii periapicale la nivelul celor două rădăcini decelabile radiologic. Din analiza imaginii radiologice (Fig. 1), rezultă că dintele 35 prezintă o anomalie de formă de tipul taurodontismului $(22,24)$, precum şi un sistem endodontic atipic cu cel puţin două canale radiculare. Conform clasificărilor uzuale din prezent, este vorba în acest caz de mezo-taurodontism (10,20). Având în vedere particularităţile anatomice, cu imposibilitatea decelării predictibile prin analiza radiografiei convenţionale (bidimensională) a configuraţiei canalelor radiculare, s-a recurs la o investigaţie imagistică suplimentară - computer tomograf cu fascicul conic (cone beam computer tomograf), datorită avantajelor conferite $(12-14,19)$. Analiza tomografiei computerizate (cone beam) confirmă anatomia complexă a dintelui de tratat şi arată prezenţa a două rădăcini cu câte un canal radicular, separaţia rădăcinilor pornind la circa 5-6 mm de apex şi configuraţie de tip ,c-shaped“ la nivelul rădăcinii vestibulare (Fig. 2a, 2b). Se constată semnele imagistice de parodontită apicală.

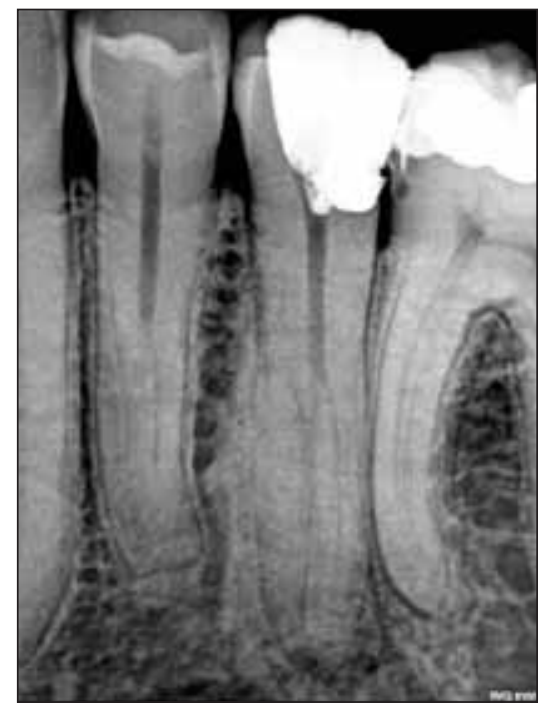

FIGURA 1. Radiografie intraorală diagnostică preoperativă a dintelui 35. Se poate constata prezența taurodontismului. Analiza radiografiei arată prezența a două rădăcini. 

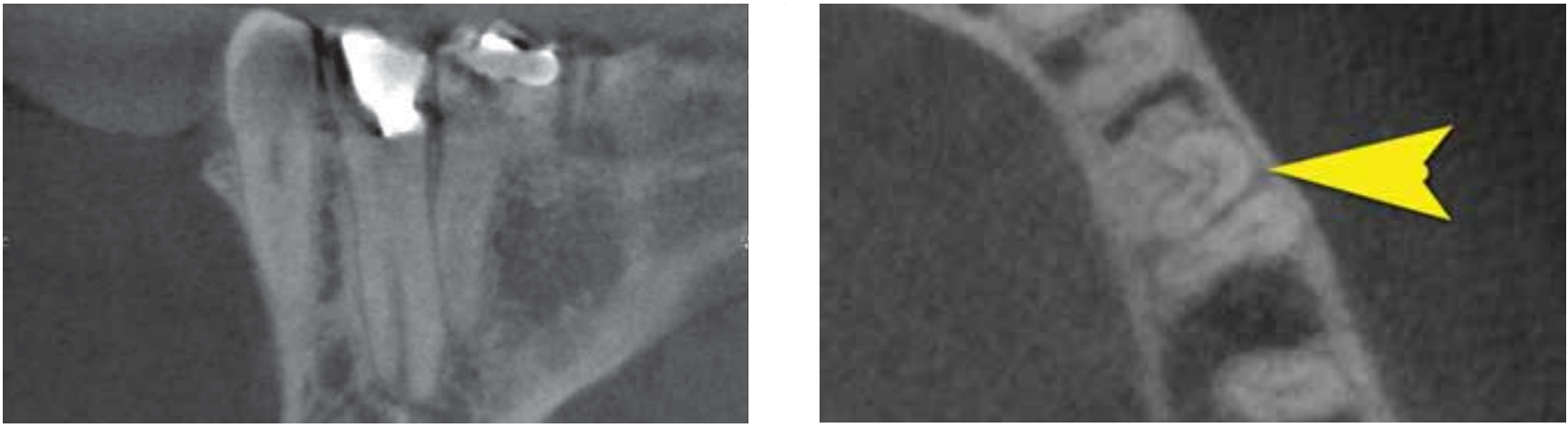

FIGURA 2. Imagini tomografice. Pe secțiune axială se pot identifica două canale radiculare separate (a). Analiza secțiunii coronale arată prezența unei configurații atipice de tipul c-shaped (b)

Diagnostic: parodontită apicală simptomatică

Tratamentul endodontic a fost iniţiat în aceeaşi şedinţă din cauza simptomatologiei dureroase. Tratamentul a fost iniţializat sub anestezie locoregională (Ultracain DS, Sanofi-Aventis, Frankfurt/M.) şi izolare a dintelui cu digă (Ultradent Corp., South Jordan, UA, USA). După îndepărtarea obturaţiei provizorii şi îndepărtarea pansamentului medicamentos, se constată supuraţie purulentă de la nivelul canalelor radicilare (Fig. 3). După extinderea cavităţii de acces iniţiale către lingual, sub control vizual continuu cu ajutorul unui microscop dentar (ProErgo, Zeiss, Oberkochen), s-a trecut la îndepărtarea secreţiei purulente şi a resturilor de ţesut necrotic din camera pulpară prin spălături intensive cu NaOCl 3,25\% parţial activat sonic (Eddy-VDW, München, Germany). După curăţarea chimică şi uscarea cavităţii, se poate vizualiza un platou de dentină la circa 16 mm sub nivelul marginii ocluzale, fără a putea fi vizualizate orificiile de acces în canalele radiculare. Prin sondare cu instrumente manuale precurbate de dimensiune ISO 008 (C-Pilot, VDW, München, Germany), au putut fi sondate iniţial trei canale radiculare. Prin instrumentare manuală, folosind instrumente de preparare radiculară de dimensiuni crescătoare până la ISO 015, sub control electrometric (Raypex 5, VDW, München, Germany), s-a creat ,glide path“ la nivelul canalelor radiculare. În continuare, canalele radiculare au fost instrumentate cu instrumente rotative din Niti într-o secvenţă hibridă utilizând FlexMaster (VDW, München, Germany), Profile şi ProTaper Next (Dentsply Maillefer, Ballaigues, Schwitzerland). În urma instrumentării şi îndepărtării mecanice a unui istm, caracteristic în cazul configuraţiei ,c-shaped“, au rezultat în final două canale radiculare se- parate. Instrumentarea rotativă s-a făcut cu un motor cu control electrometric continuu (VDW Gold, VDW, München, Germany). În timpul preparării canalelor radiculare, a putut fi vizualizată conformaţia atipică de tip „c-shaped“ a canalului vestibular, ceea ce a impus intensificarea lavajului endodontic. După fiecare schimb de instrumente, s-a folosit pentru lavaj $\mathrm{NaOCl} 3,25 \%$ parţial activat sonic. După tratamentul chemomecanic, canalele au fost uscate cu conuri de hârtie sterile şi apoi a fost aplicat pentru o săptămână o pastă de hidroxid de calciu radioopacă (Ultracal, Ultradent Corp., South Jordan, UA, USA), iar cavitatea de acces a fost sigilată adeziv cu un ciment glassionomer (Fuji II, GC Corporation, Tokyo, Japan).

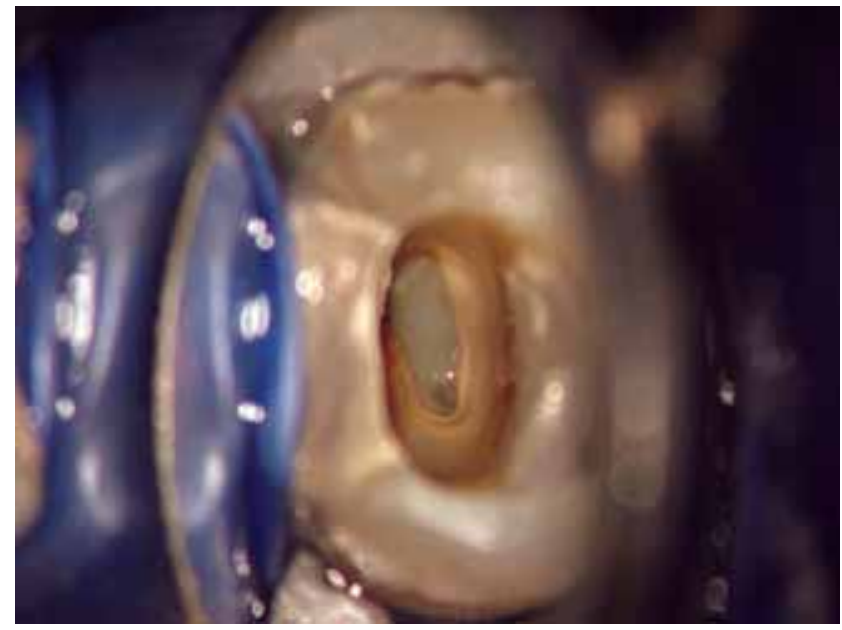

FIGURA 3. Imaginea clinică sub microscop după îndepărtarea obturației provizorii. Se poate vedea exsudatul purulent la nivelul camerei pulpare

La o săptămână după şedinţa anterioară, pacientul relatează că dintele este asimptomatic. Sub anestezie locoregională şi izolare cu ajutorul digii, a fost continuat tratamentul endodontic. Prepararea canalelor a fost finalizată cu instrumente de Niti 
ProTaper Next X4 sub control electrometric continuu. După irigaţie cu NaOCl 3,25\% parţial activat sonic a fost efectuată o radiografie cu conuri de gutapercă (masterpoint) pentru verificarea radiografică a lungimii instrumentării (Fig. 4). După uscarea canalelor radiculare, acestea au fost obturate termoplastic cu gutapercă şi AH+ (Dentsply Maillefer, Ballaigues, Schwitzerland) ca sealer după o tehnică Schilder (21) modificată de Tulus pentru un sistem canalar endodontic complex (23). În prima fază, s-a efectuat obturaţia canalelor în porţiunea apicală până la nivelul bifurcării canalelor. După această fază de down-pack, s-a procedat la injectarea de gutapercă termoplasticată pînă la 3 $\mathrm{mm}$ sub nivelul joncţiunii smalţ-cement. În final, s-a procedat la sigilarea obturaţiei de canal cu compozit cu fluiditate medie cu radioopacitate similară dentinei şi reconstrucţia dintelui cu compozit în tehnică adezivă, urmată de control radiologic (Fig. 5). Imaginea radiologică a obturaţiei canalului vestibular, cu un contur neregulat, este specifică tipului de configuraţie c-shaped, care nu poate fi instrumentat complet mecanic şi indică în acelaşi timp o îndepărtare chimică a ţesuturilor intracanalare moi prin tratamentul chimic.

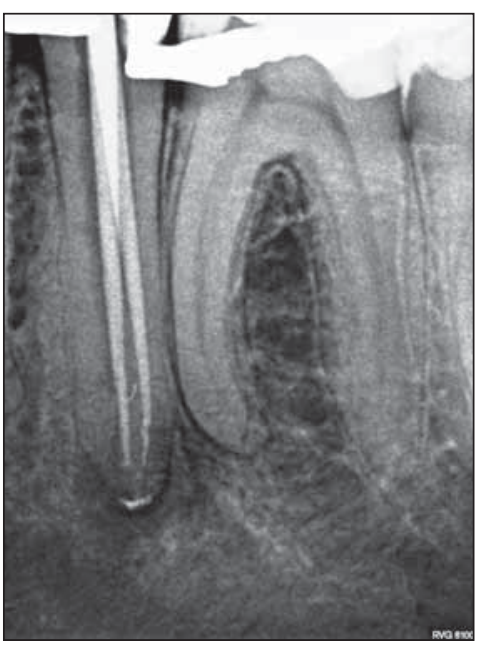

FIGURA 4. Control radiologic al lungimii de lucru cu conuri de gutapercă. Se constată resturi de hidroxid de calciu în spatiul periradicular, precum si interradicular
La un an după tratamentul endodontic, a fost efectuat un control clinic şi radiologic. Conform pacientului, dintele este asimptomatic, examenul clinic şi cel radiologic (Fig. 6) nu prezintă semne de modificări patologice. Pentru minimizarea riscului de fractură, s-a recomandat protejarea dintelui cu o coroană de înveliş, manoperă ce urmează să fie efectuată de către protetician.

La trei şi respectiv cinci ani după tratament, s-au efectuat controale alw dintelui tratat. Dintele a fost

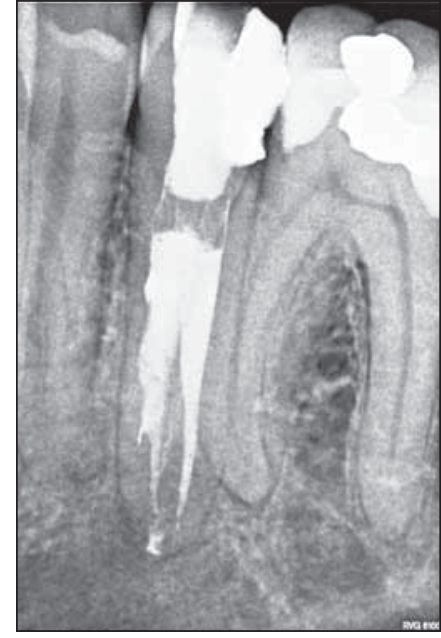

FIGURA 5. Control radiologic postoperativ al dintelui 35

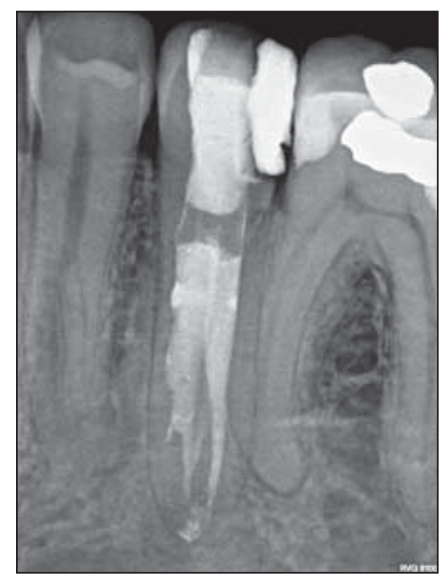

FIGURA 6. Radiografie de control postendodontic al dintelui 35 la un an după tratament. Nu se constată semne radiologice de afecțiuni apicale

între timp acoperit cu o coroană de înveliş. Examenele clinice şi radiologice (Fig. 7 şi 8 ) nu prezintă semne de modificări patologice.

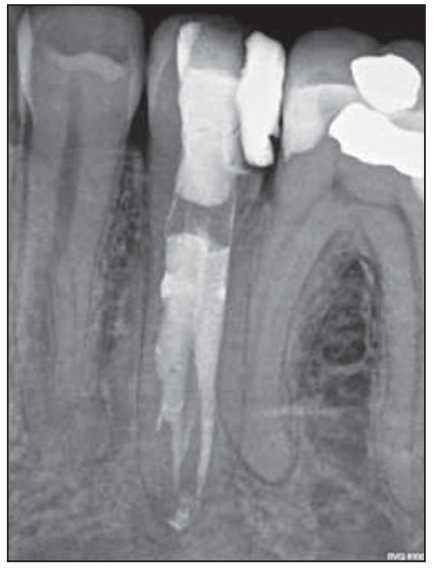

FIGURA 7. Radiografie de control postendodontic al dintelui 35 la trei ani după tratament. Se constată acoperirea dintelui cu o coroană de înveliş. Nu se constată semne radiologice de afecțiuni apicale

\section{DISCUTुII}

Articolul de faţă descrie succesul tratamentului endodontic al unui dinte cu o morfologie atipică. Taurodontismul este o afecţiune foarte rară, întâlnită mai frecvent la molări decât la premolari. În ca- 


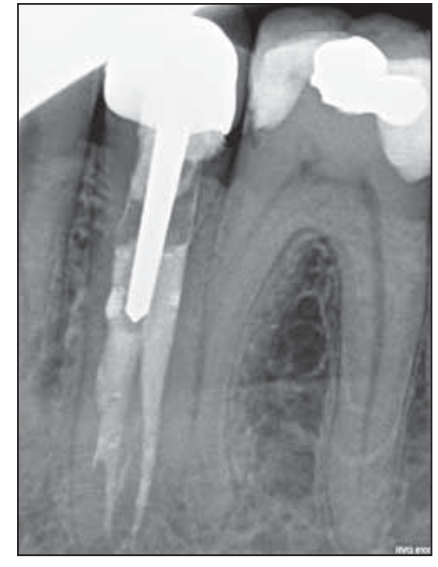

FIGURA 8. Radiografie de control postendodontic al dintelui 35 la cinci ani după tratament. Nu se constată semne radiologice de afecțiuni apicale

zul premolarilor, diagnosticul nu se poate pune clinic, ci numai pe baza analizei radiografiei.
Prevalenţa premolarilor inferiori cu rădăcini separate apical este, de asemenea, foarte rară. Prevalenţa acestui tip de combinaţie de rarităţi se pare că nu a fost analizată statistic. Există un consens între autori, că atât tratamentul endodontic al dinţilor care prezintă taurodontism, cât şi al premolarilor inferiori cu mai multe canale separate este extrem de dificil şi că un diagnostic iniţial corect, inclusiv utilizând imagistica tridimensională, este imperios necesar $(2,4-6,9)$. Succesul tratamentului prezentat se datorează şi utilizării continue a microscopului dentar, ca şi utilizării unei tehnici speciale pentru obturaţia de canal.

Conflict of interest: none declared Financial support: none declared

\section{BIBLIOGRAFIE}

1. Bharti R., Chandra A., Tikku A.P., Arya D. Prevalence of taurodont molars in a North Indian population. Indian Journal of Dentistry 2015; 6: 27-31

2. Borges A.H., Mamede-Neto I., Volpato L.E.R., Pedro F.L.M., Bueno M.R., Estrela C. Using cone beam computed tomography images to diagnose multiple taurodontisms. Gen Dent 2014; 62: e20-2

3. Bürklein S., Breuer D., Schäfer E. Prevalence of taurodont and pyramidal molars in a German population. J Endod 2011; 37: $158-162$

4. C. do Nascimento, A.F. Marques, C. Sponchiado-Junior, F.R. Garcia, M.A. de Carvalho. Endodontic Treatment of Hypertaurodontic Mandibular Molar Using Reciprocating Single-file System: A Case Report. Bull Tokyo Dent Coll 2016; 57: 83-89

5. Demiryurek E.O., Gonulol N., Bulucu B. Endodontic treatment of a taurodontic premolar with five canals. Aust Endod J 2013; 39: 81-84

6. Dineshshankar J., Sivakumar M., Balasubramanium A.M., Kesavan G., Karthikeyan M., Prasad V.S. Taurodontism. J Pharm Bioallied Sci 2014; 6: S13-5

7. EIDeeb M.E. Three root canals in mandibular second premolars: literature review and a case report. J Endod 1982; 8: $376-377$

8. Jafarzadeh H., Azarpazhooh A., Mayhall J.T. Taurodontism: A review of the condition and endodontic treatment challenges. Int Endod J 2008; 41: 375-388

9. Jayashankara C., Shivanna A.K., Sridhara K., Kumar P.S. Taurodontism: A dental rarity. J Oral Maxillofac Pathol 2013; 17: 478

10. Keene H.J. A morphologic and biometric study of taurodontism in a contemporary population. Am J Phys Anthropol. 1966: 208-209

11. Kerekes K., Tronstad L. Morphometric observations on root canals of human premolars. J Endod 1977; 3: 74-79

12. Kottoor J., Albuquerque D., Velmurugan N., Kuruvilla J. Root anatomy and root canal configuration of human permanent mandibular premolars: a systematic review. Anat Res Int 2013; 2013: 254250

13. Kottoor J., Velmurugan N., Surendran S. Endodontic management of a maxillary first molar with eight root canal systems evaluated using cone-beam computed tomography scanning: a case report. J Endod 2011; 37: 715-719

14. Levin A., Shemesh A., Katzenell V., Gottlieb A., Ben Itzhak J., Solomonov M. Use of Cone-beam Computed Tomography during Retreatment of a 2-rooted Maxillary Central Incisor: Case Report of a Complex Diagnosis and Treatment. J Endod 2015; 41: 2064-2067

15. Llamas R., Jimenez-Planas A. Taurodontism in premolars. Oral Surg Oral Med Oral Pathol 1993; 75: 501-505

16. MacDonald-Jankowski D.S., Li T.T. Taurodontism in a young adult Chinese population. Dentomaxillofac Radiol 1993; 22: 140-144

17. Ruprecht A., Batniji S., el-Neweihi E. The incidence of taurodontism in dental patients. Oral Surg Oral Med Oral Pathol 1987; 63: 743-747

18. Sarr M., Toure B., Kane A.W., Fall F., Wone M.M. Taurodontism and the pyramidal tooth at the level of the molar. Prevalence in the Senegalese population 15 to 19 years of age. Odontostomatol Trop 2000; 23: 31-34

19. Scarfe W.C., Levin M.D., Gane D., Farman A.G. Use of Cone Beam Computed Tomography in Endodontics. International Journal of Dentistry 2009; 2009: 634567

20. Schifman A., Chanannel I. Prevalence of taurodontism found in radiographic dental examination of 1200 young adult Israeli patients. Community Dent Oral Epidemiol. 1978;6:2003 1978: 200-203

21. Schilder H. Filling root canals in three dimensions. Dent Clin North Am 1967: 723-744

22. Shaw J.C. Taurodont teeth in South African races. Journal of Anatomy 1928; 62: 476-498

23. Tulus G., Weber T., Petrovits A. Diagnosis and Therapy of branched Root Canal Systems. ENDO (Lond Engl) 2015; 9: 267-282

24. Witkop C.J. Jr. Manifestation of genetic disease in the human pulp. Oral Surgery, Oral Medicine and Oral Pathology 1971: 278-316

25. Zillich R., Dowson J. Root canal morphology of mandibular first and second premolars. Oral Surg Oral Med Oral Pathol 1973; 36: 738-744 